\title{
Experimental verification of the joints strength features in the quality control of the mass- produced upholstery frames
}

\author{
Ewa Skorupińska ${ }^{1, *}$, Krzysztof Wiaderek ${ }^{1}$, tukasz Matwiej $^{2}$, and Maciej Sydor ${ }^{3}$ \\ ${ }^{1}$ Euroline sp. z o.o., Leszno, \\ ${ }^{2}$ Uniwersytet Przyrodniczy w Poznaniu, Wydział Leśny i Technologii Drewna, Katedra Meblarstwa, \\ Poznań, \\ ${ }^{3}$ Uniwersytet Przyrodniczy w Poznaniu, Wydział Leśny i Technologii Drewna, Katedra Obrabiarek \\ i Podstaw Konstrukcji Maszyn, Poznań, ORCID 0000-0003-0076-3190
}

\begin{abstract}
An upholstery frame is an element of upholstery furniture, which is heavily loaded with forces. Critical to the quality of the frame is the load capacity of the connections of its structure elements. Moreover an important issue is the repeatability of the suitable strength in the whole production batch. Tested wooden frame joints were made with glue and staples. The goal of our study was to compare the strength of the joints made by a man and by a robot in industrial mass production. The laboratory test was done on an universal testing machine which measure the stress-strain characteristics showing the yield behaviour of test samples. The results show that a "robotic technology" gives slightly higher strength values than the manual production. It was also observed that the force value distributions in compared two series of samples have different nature in the both technologies. Based on the observation of the technologies and based on the analysis of the research results, it was found that the reason for this is the greater constancy of technological parameters in robotic production (in the described case, the bigger variability of the strength of connections made by man was caused by the different exposure time of the adhesive to drying, while in "robotic" production gluing, was done in the same throughout the long production series).
\end{abstract}

\section{Introduction}

An upholstery frame is a typical part of an upholstery furniture, which is high loaded when using the furniture. Typical damage of an upholstery frame is the broken corner connection in the rectangle frame. Those connections are critical to quality of the frame [1]. The main quality criteria of those frames are load capacity and reliability of connections in wooden structural elements. Second, the supporting factor is the repeatability of strength ability within production batch. Frame connections are provided with using glue and construction of finger joints. Within those measurements is provided a comparison of reference samples

* Corresponding author: ewa.skorupinska@up.poznan.pl 
provided in a manual technology with samples provided in the robotic production process and samples provided in the manual production process.

The main goal of this study is comparison of strenght upholstery frames of the same construction in two different mass production processes, in a manual and in a robotic technology.

\section{Materials}

Analysed upholstery frame is a rectangular furniture piece made from wooden, metal and plastic parts with overall dimensions around $130 * 65$ (depends on which part it is). In the middle of the long sides of the frame there is a metal crossbar, which transfers some of the forces from the springs, the crossbar is fastened with two $4.0 \times 35$ wood screws. The zig-zag springs are made from 3,8 mm cold rolled steel wire (EN 10270-1), their ends are placed in plastic spring holders which are fixed to the frame with two metal staples. The described frame is shown in Figure 1.

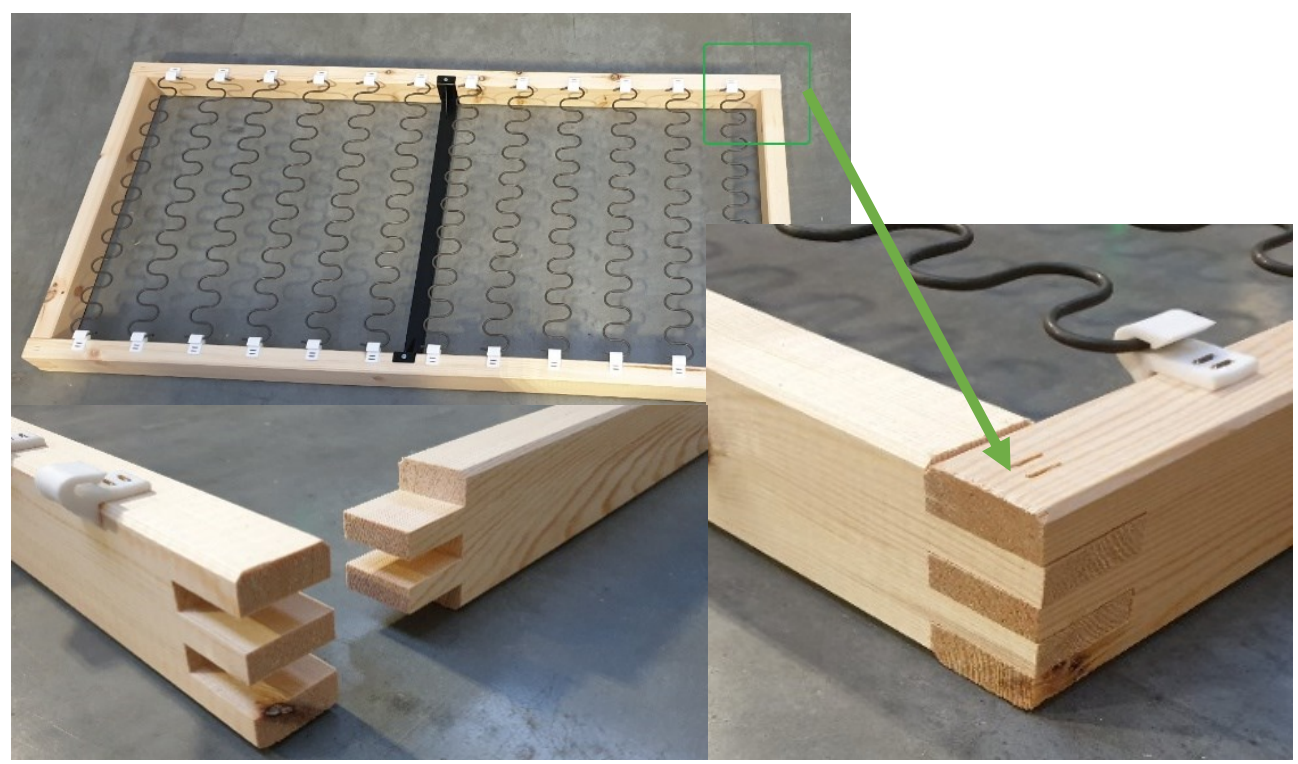

Fig. 1. Upholstery frame and its corner connection

The subject of the research was the samples of corner joints of the frames. The analysed joints were double "tongue and grove", made with Libracol 2.10 glue and four $38 \mathrm{~mm}$ staples (two per side). The cross section of joints was $65 \times 36 \mathrm{~mm}$. The test sample is shown in figure 2 .

\section{Methods}

Two 24 piece series of samples were tested. The samples were from industrial mass production: the first serie were "man-made", the second were "robot-made". The results of the tests were compared with the previous test results concerning the connections of the same construction produced in laboratory conditions in 2018 (these results were published in 2018, as a part of another study [2]). The series of the samples were marked respectively: "2020: F1 man-made", "2020: F1 robot-made", "2018: F1 man-made". 
All samples were stretched (pulled apart) (fig. 2). The stretched force applied by the laboratory universal test machine increased until the maximum force. The breaking force was denoted as $F_{1}$ and maximum force was denoted as $F_{2}$ (the braking force is the force which did not cause permanent damage to the connection). Measurements were provided in temperature $21^{\circ} \mathrm{C}$ with speed of traverse movement $25 \mathrm{~mm} / \mathrm{min}$.

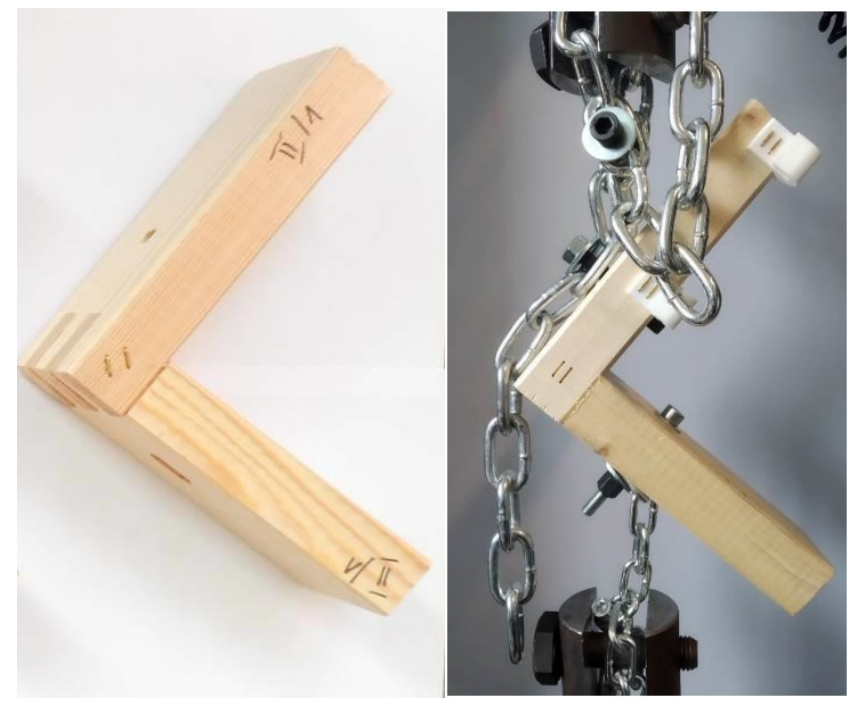

Fig. 2. Test samples

The force $F_{1}$ was taken for further analysis ( $F_{1}$ show usable strength of the connection).

\section{Results and analyses}

Results of experiments are presented on Figure 3.

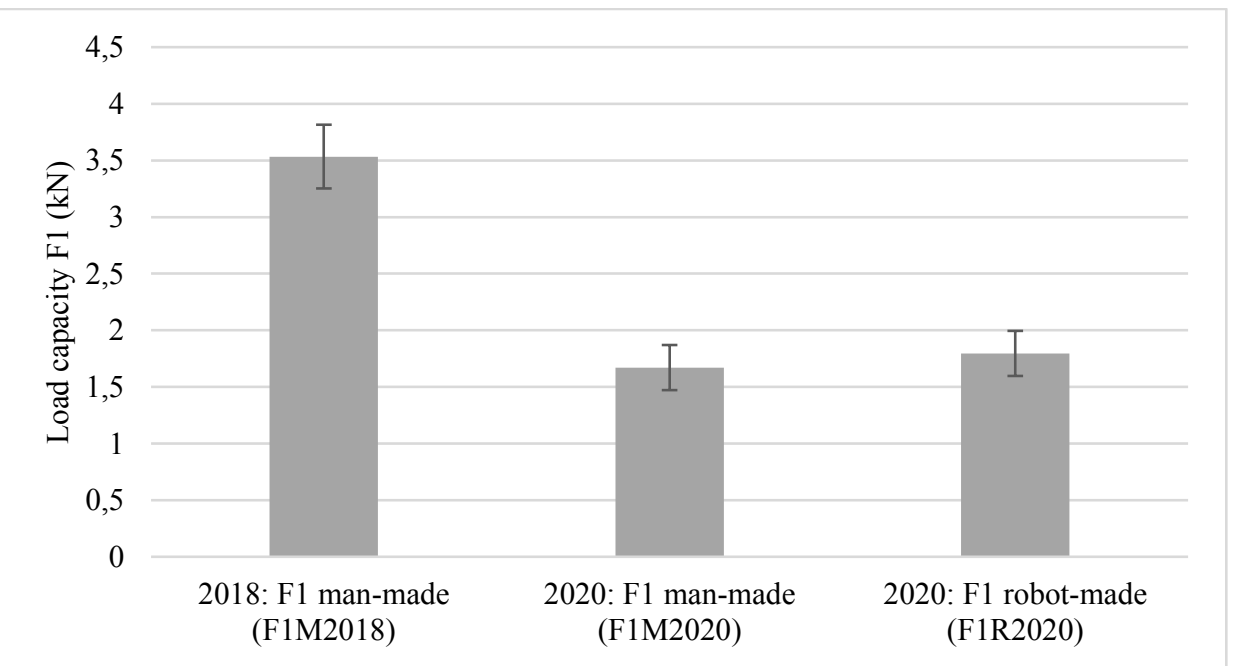

Fig. 3. Mean load capacity of the series (error bars show standard deviations) 
Results labeled "2020: F1 man-made" and "2020: robot-made" represent the result of our own research [3]. Fig. 3 presents the results of earlier tests, carried out on samples of the same design, but produced in a laboratory, for comparison [2].

Figure 4 presents histograms showing participation of force in particular intervals for both series from 2020, F1 man-made and F1 robot-made.

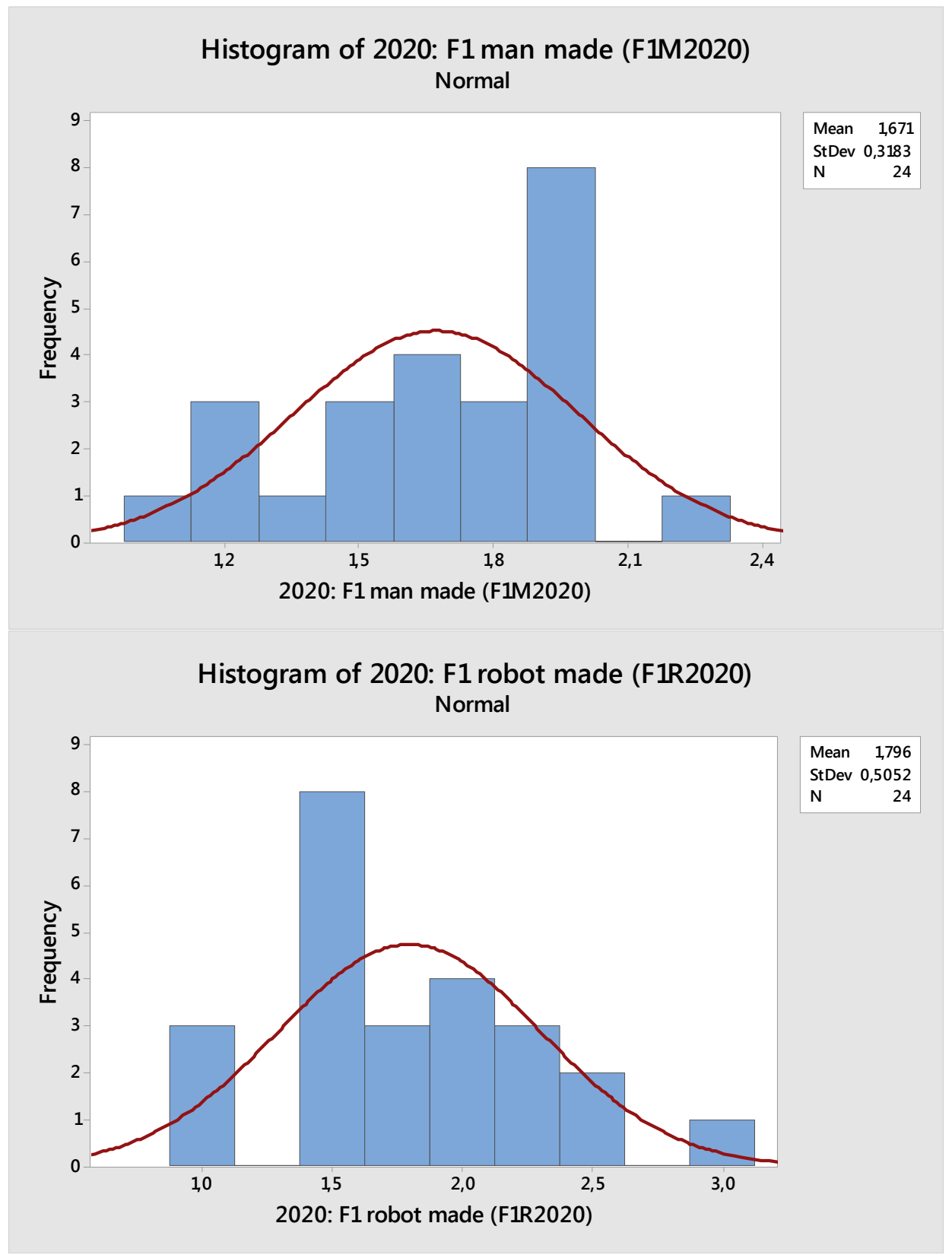

Fig. 4. Histograms presents participation of force for samples from manual and robotic production 
On Figure 4 it can be observed different participation of force for both compared samples. Results were analysed by another statistic method. In table 1 are input data's for univariate Anova analysis as in Tabele 1 . Summary of data for statistical analysis

Table 1 . Summary of data for statistical analysis

\begin{tabular}{rcccc}
\hline Groups & Count & Sum & Average $(\mu)$ & Variance \\
\hline 2018: F1 man (F1M2018) & 12 & 42,4 & 3,5333333 & 0,486061 \\
2020: F1 man (F1M2020) & 24 & 40,1 & 1,6708333 & 0,101286 \\
2020: F1 robot (F1R2020) & 24 & 43,1 & 1,7958333 & 0,255199 \\
\hline
\end{tabular}

One-way ANOVA. Unequal variances were assumed for the analysis.

Table 2. ANOVA parameters

\begin{tabular}{lrrrrrr}
\hline \multicolumn{1}{c}{ Source of Variation } & \multicolumn{1}{c}{$S S$} & $d f$ & \multicolumn{1}{c}{ MS } & $F$ & P-value & F crit \\
\hline Between Groups & 31,2915 & 2 & 15,64575 & 65,83631 & $1,53 \mathrm{E}-15$ & 3,158843 \\
Within Groups & 13,54583 & 57 & 0,2376462 & & & \\
Total & 44,83733 & 59 & & & & \\
\hline
\end{tabular}

The hipothesis: H0: $\mu_{1}=\mu_{2}=\mu_{3} ; \mathrm{H} 1$ : at least one of the means is different. Significance level $\alpha=0,05$. After ANOVA analysis it was found that $\mathrm{F}>\mathrm{F}$ crit, therefore the null hypothesis was rejected (in this case: $65.836>3.159$ ). The means of the three series of samples are not all equal. At least one of the means is different. However, the ANOVA does not tell where the difference lies. It was decided to perform a t-Test to test two chosen pair of means.

Test t: two samples assuming (F1M2020 vs. F1R2020) unequal variances.

Table 3. T test parameters

\begin{tabular}{lcc}
\hline & $F 1 M 2020$ & F1R2020 \\
\hline Mean $(\mu)$ & 1,670833 & 1,795833 \\
Variance & 0,101286 & 0,255199 \\
Observations & 24 & 24 \\
Hipotesized mean difrence & 0 & \\
df & 39 & \\
t Stat & $-1,02564$ & \\
$\mathrm{P}(\mathrm{T}<=\mathrm{t})$ one-tail & 0,155691 & \\
Test T one-tail & 1,684875 & \\
$\mathrm{P}(\mathrm{T}<=\mathrm{t})$ two-tail & 0,311381 & \\
Test t two-tail & 2,022691 & \\
\hline
\end{tabular}

The hypothesis: H0: $\mu_{1}-\mu_{2}=0 ; \mathrm{H} 1: \mu_{1}-\mu_{2} \neq 0$ '

Result of $t$ test: A two-tail test (inequality) was performed. If $\mathrm{t}$ Stat $<-t$ Critical two-tail or $t$ Stat $>\mathrm{t}$ Critical two-tail, the null hypothesis is rejected. This is not the case (in the analysis the result was obtained: $-2.022691<-1.02564<2.022691$ ). Therefore, the null hypothesis 
was not rejected. The observed difference between the sample means $(1.670833-1.795833)$ is not convincing enough to conclude that the mean force F1 in the corner joints of man-made frames (F1M2020) differs significantly from the force F1 in the joints of the frames made by robots (F1R2020).

\section{Discussion}

During the tests, as in the publication [2], two forces were observed: the force $F_{1}$ was the force after which the adhesive joint cracked, while the force $F_{2}$ was the force that pulled out the metal staples. Exceeding the $F_{1}$ force causes permanent destruction of the connection sample. Therefore, as mentioned in the methodology, the values of the force F1 were analyzed.

The results of the experiments show that:

1. The laboratory man-made samples (F1M2018) have higher strength than samples produced in industrial conditions (F1M2020 and F1R2020)

2. The industrial man-made samples F1M2020 have an average strength similar to that of robot-made samples F1R2020.

3. The histograms of the F1 force values are different from for manual production (F1M2020) and for robotic production (F1R2020).

In the analyses were compared data's and strength parameter stability corner joints produced in two technologies. The results show as robotic production has a smaller spread of measured strength parameters than manual production. Also in samples from robotic production it can be seen slighty higher values of strength than in manual produced samples. Probably the reason for this is the greater constancy of technological parameters in robotic production.

\section{Conclusions}

The main result of the measurements is identification and described influence of gluing application methodology on strength of the corner connection. As a result of provided measurements observed: higher strength of corner connection and smaller spread of strength in series. The reason of that are following:

1. In robotic production process glue application is in closed system. In manual production process glue application is provided manually from dedicated containers, application by brush. Open time for the glue is under control, anyway wooden elements with applied glue are affected on water evaporation from the glue what has an influence on strength of the corner connection.

2. In robotic production process glue is in closed system. Right after glue application comes finger joints connection. Glue is not affected on premature water evaporation and premature adhesive binder.

3. The robotic production process is scricty standardised and repeatable, while the manual production process have more variables: man, glue application methodology, working routines, securing glue from water evaporation, steps sequence of using elements with applied glue, securing open time for the glue. In robotic production process are: described and repeatable glue amount, close gluing system which secure keeping glue parameters on required level.

The work present results of the project POIR.01.01.0100-0152/17 "Development and implementation to business practice of Euroline innovative way of production upholstery frames with zig-zag springs as a raw material in production process of upholstery furniture, which could increase the productivity, 
efficiency and quality of the production upholstery frames as an answer for market requirements of increasing the supply".

\section{References}

1. K. Wiaderek, Ł. Matwiej, M. Sydor, and E. Skorupińska, "Analiza jakości montażu ram mebli tapicerowanych w zrobotyzowanym procesie produkcji / Analysis of the assembly quality of upholstered furniture frames in a robotic production process," in Projektowanie i Eksploatacja Maszyn Roboczych, T. Lagoda, M. Kurek, and A. Kurek, eds., Studia i Monografie; Politechnika Opolska; Zeszyt 542 No. Vol. 2, pp. 273-281, ISSN 1429-6063 (Oficyna Wydawnicza Politechniki Opolskiej, 2020).

2. Ł. Matwiej, K. Wiaderek, E. Skorupińska, and M. Sydor, "Strength testing of upholstery frame connections and spring holders," Ann. WULS - SGGW For. WoodTechnol. p.579-592 (2018).

3. D. Andrzejewski, Sprawozdanie z Badań Próbek Połaczeń i Zaczepów Sprężyn (INOP, 2020). 